\title{
Real-Time Visualization of Diffusion-Controlled Nanowire Growth in Solution
}

\author{
Shengrong Ye, ${ }^{\perp, \dagger}$ Zuofeng Chen, ${ }^{\perp, \dagger, \dagger}$ Yoon-Cheol Ha, ${ }^{\perp, \dagger, \S}$ and Benjamin J. Wiley ${ }^{* \dagger}$ \\ ${ }^{\dagger}$ Department of Chemistry, Duke University, Durham, North Carolina 27708, United States \\ ${ }^{\ddagger}$ Department of Chemistry, Tongji University, Shanghai 200092, China \\ ${ }^{\S}$ Creative and Fundamental Research Division, Korea Electrotechnology Research Institute, Changwon 642-120, Republic of Korea
}

Supporting Information

ABSTRACT: This Letter shows that copper nanowires grow through the diffusion-controlled reduction of dihydroxycopper(I), $\mathrm{Cu}(\mathrm{OH})_{2}{ }^{-}$. A combination of potentiostatic coulometry, UV-visible spectroscopy, and thermodynamic calculations was used to determine the species adding to growing $\mathrm{Cu}$ nanowires is $\mathrm{Cu}(\mathrm{OH})_{2}{ }^{-}$. Cyclic voltammetry was then used to measure the diffusion coefficient of $\mathrm{Cu}(\mathrm{OH})_{2}{ }^{-}$in the reaction solution. Given the diameter of a $\mathrm{Cu}$ nanowire and the diffusion coefficient of $\mathrm{Cu}(\mathrm{OH})_{2}{ }^{-}$, we calculated the dependence of the diffusion-limited growth rate on the concentration of copper ions to be $26 \mathrm{~nm} \mathrm{~s} \mathrm{mM}^{-1}$.

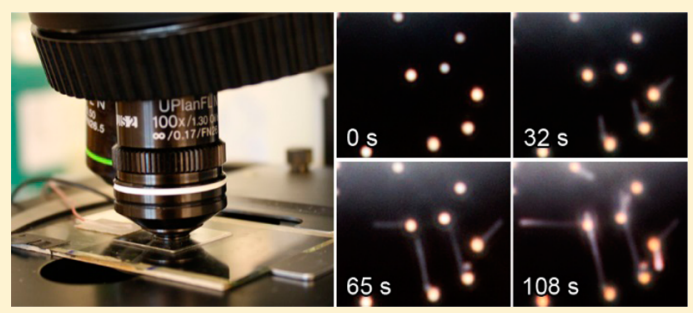
Independent measurements of the nanowire growth rate with dark-field optical microscopy yielded $24 \mathrm{~nm} \mathrm{~s}^{-1} \mathrm{mM}^{-1}$ for the growth rate dependence on the concentration of copper. Dependence of the nanowire growth rate on temperature yielded a low activation energy of $11.5 \mathrm{~kJ} \mathrm{~mol}^{-1}$, consistent with diffusion-limited growth.

KEYWORDS: anisotropic assembly, growth mechanism, copper nanowires, diffusion control, real time visualization

$S^{c}$ elf-assembly is the spontaneous organization of components such as atoms and molecules into patterns or structures (e.g., crystals) without human intervention. ${ }^{1,2}$ In the past decade, the number of syntheses available that enable control over the anisotropic self-assembly of atoms into nanostructures has increased from less than a dozen to thousands. $^{3-9}$ The ability to make and use anisotropic nanostructures has advanced tremendously, but the degree to which the growth process is understood depends upon the synthetic methodology. For nanowire growth in the vapor phase, it is generally recognized that semiconductor nanowires grow via a process in which material in the vapor phase is incorporated into a growing nanowire via nanoparticle catalysts. $^{10-12}$ For self-assembly in the liquid phase, CdTe nanowires, iron oxyhydroxide nanowires, and $\mathrm{PbSe}$ nanorods have been shown to grow through the oriented attachment of smaller spherical nanoparticles. ${ }^{13-15} \mathrm{Bi}_{2} \mathrm{~S}_{3}$ nanowires have recently been shown to exhibit polymer-like nanowire growth kinetics. ${ }^{16}$ In constrast, for metal nanowires, it is not clear whether the species adding to the nanostructure consists of metal ions, reduced metal atoms, or metal clusters. In addition, it is not clear what mechanistic step limits the rate of nanostructure growth.

Metal nanowires have the potential to be a low cost replacement for the transparent conductor, indium tin oxide (ITO), in touch screens, flat-panel displays, thin-film solar cells, and organic light emitting diodes. ${ }^{17-20}$ Improving the properties and cost of nanowire-based transparent electrodes requires greater control over the structure and yield of nanowires in solution phase syntheses, which in turn motivates mechanistic studies of nanowire growth in solution. However, as the growth of metal nanowires has generally been difficult to observe in real time, there is as yet very little quantitative analysis of nanowire growth kinetics in solution, let alone a clear relationship between the growth kinetics and nanostructure morphology. ${ }^{11,21-25}$ The recent development of in situ transmission electron microscopy (TEM) and transmission Xray microscopy (TXM) has enabled the real time visualization of spherical nanoparticle and nanorod growth in a liquid environment, semiconductor nanowire growth in the vapor phase, as well as the galvanic replacement reaction between $\mathrm{Ag}$ nanowires and $\mathrm{HAuCl}_{4} \cdot{ }^{11,12,21,24,26-33}$ TEM or TXM-based visualization has yet to be applied to the solution-phase growth of nanowires, perhaps due to the lack of temperature control and the high cost of the current technology.

$\mathrm{Cu}$ nanowires synthesized through the ethylenediamine(EDA-) mediated approach have previously been shown to grow along the [110] direction with a 5-fold twinned crystal structure. ${ }^{34-36}$ This growth direction and crystal structure is the same as for Ag nanowires grown with a polyol synthesis using polyvinylpyrrolidone (PVP) as a capping agent. ${ }^{37}$ Similar to the case of Ag nanowires and PVP, it has been hypothesized that EDA preferentially binds to the higher surface energy $\{100\}$ facets that make up the sides of the wire, leaving the lower energy $\{111\}$ facets on the ends of the nanowire open to

Received: May 12, 2014

Revised: June 30, 2014

Published: July 23, 2014 

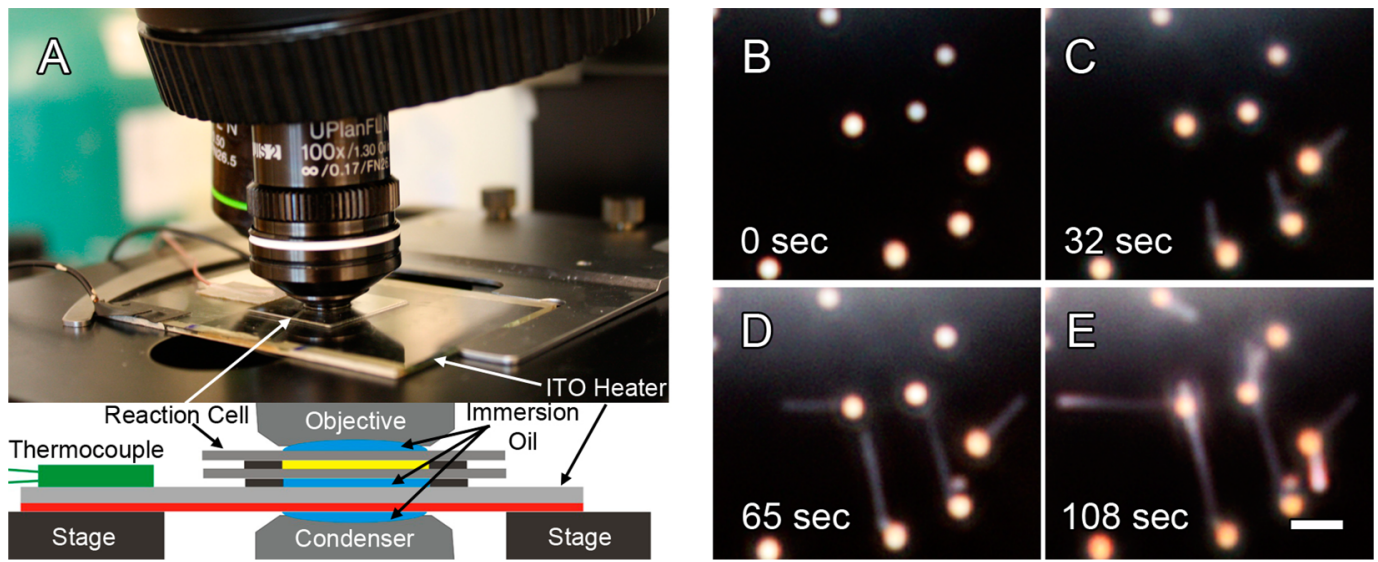

Figure 1. (A) Camera image and schematic cross-sectional view of the reaction cell with the dark field optical microscope. Real time growth of $\mathrm{Cu}$ nanowires recorded at (B) 0, (C) 32, (D) 65, and (E) $108 \mathrm{~s}$. Scale bar is $2 \mu \mathrm{m}$.
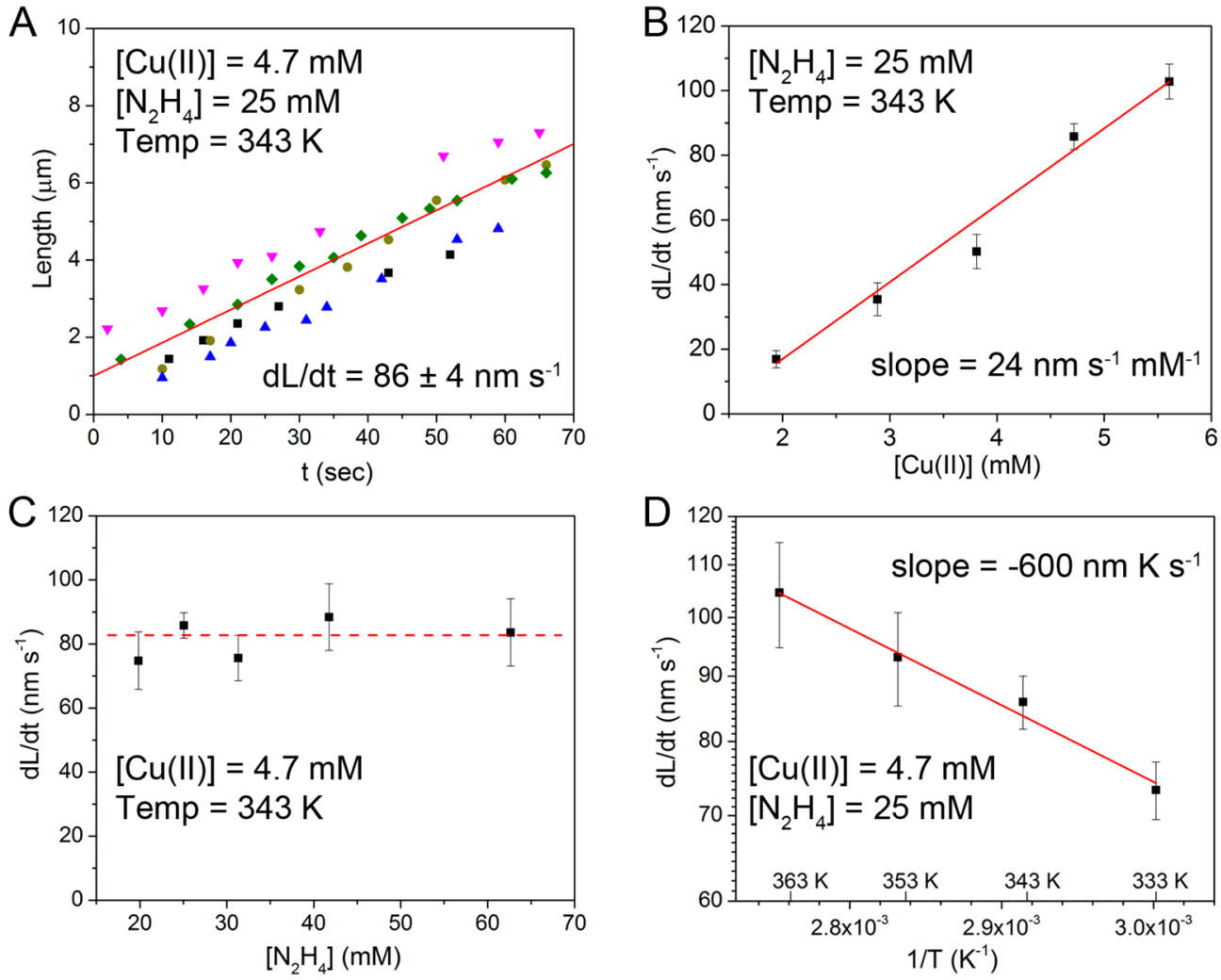

Figure 2. (A) Plot of length versus time for five $\mathrm{Cu}$ nanowires. Dependence of the growth rate on the (B) $[\mathrm{Cu}(\mathrm{II})],(\mathrm{C})\left[\mathrm{N}_{2} \mathrm{H}_{4}\right]$, and $(\mathrm{D})$ temperature. Each data point and error bar in parts $\mathrm{B}-\mathrm{D}$ represents the average and standard deviation of ten measurements.

atomic addition. Indeed, it has previously been shown that increasing the concentration of EDA in the $\mathrm{Cu}$ nanowire synthesis decreases the rate of addition of $\mathrm{Cu}$ to the ends of the nanowires. ${ }^{38}$ However, it was not clear what species was adding to the nanowire or what mechastic step limited its rate of growth.

Here we introduce a growth model derived from real time observation of $\mathrm{Cu}$ nanowire growth in solution with dark field optical microscopy (DFOM). ${ }^{38}$ By enabling the measurement of the axial growth rate of nanowires in real time, DFOM provides a way to probe the reaction mechanism under a variety of conditions quickly, and at relatively low cost. By using $\mathrm{DFOM}$ to observe the growth rates of $\mathrm{Cu}$ nanowires grown at various reaction temperatures, concentrations of $\mathrm{Cu}\left(\mathrm{NO}_{3}\right)_{2}$, and concentrations of $\mathrm{N}_{2} \mathrm{H}_{4}$, we determined that $\mathrm{Cu}$ nanowires grow through the diffusion limited reduction of $\mathrm{Cu}(\mathrm{OH})_{2}{ }^{-}$.

The initial formation of $\mathrm{Cu}$ seed particles and subsequent nanowire growth can be visualized in a reaction cell situated in the viewing plane of a dark field optical microscope (see Figure $1 \mathrm{~A}$, experimental details are given in the Supporting Information). The reaction solution is made by mixing $\mathrm{NaOH}, \mathrm{Cu}\left(\mathrm{NO}_{3}\right)_{2}, \mathrm{EDA}$, and $\mathrm{N}_{2} \mathrm{H}_{4}$ in water at room temperature. A typical nanowire growth process (see Movie S1, Supporting Information) at $343 \mathrm{~K}$ was recorded at rate of 1 frame per second. Four frames extracted at $0,32,65$, and $108 \mathrm{~s}$ are shown in Figure 1B-E. Here, $0 \mathrm{~s}$ is chosen as the last frame in which no nanowire is visible. The reaction temperature was monitored by a thermocouple situated next to the cell; this 

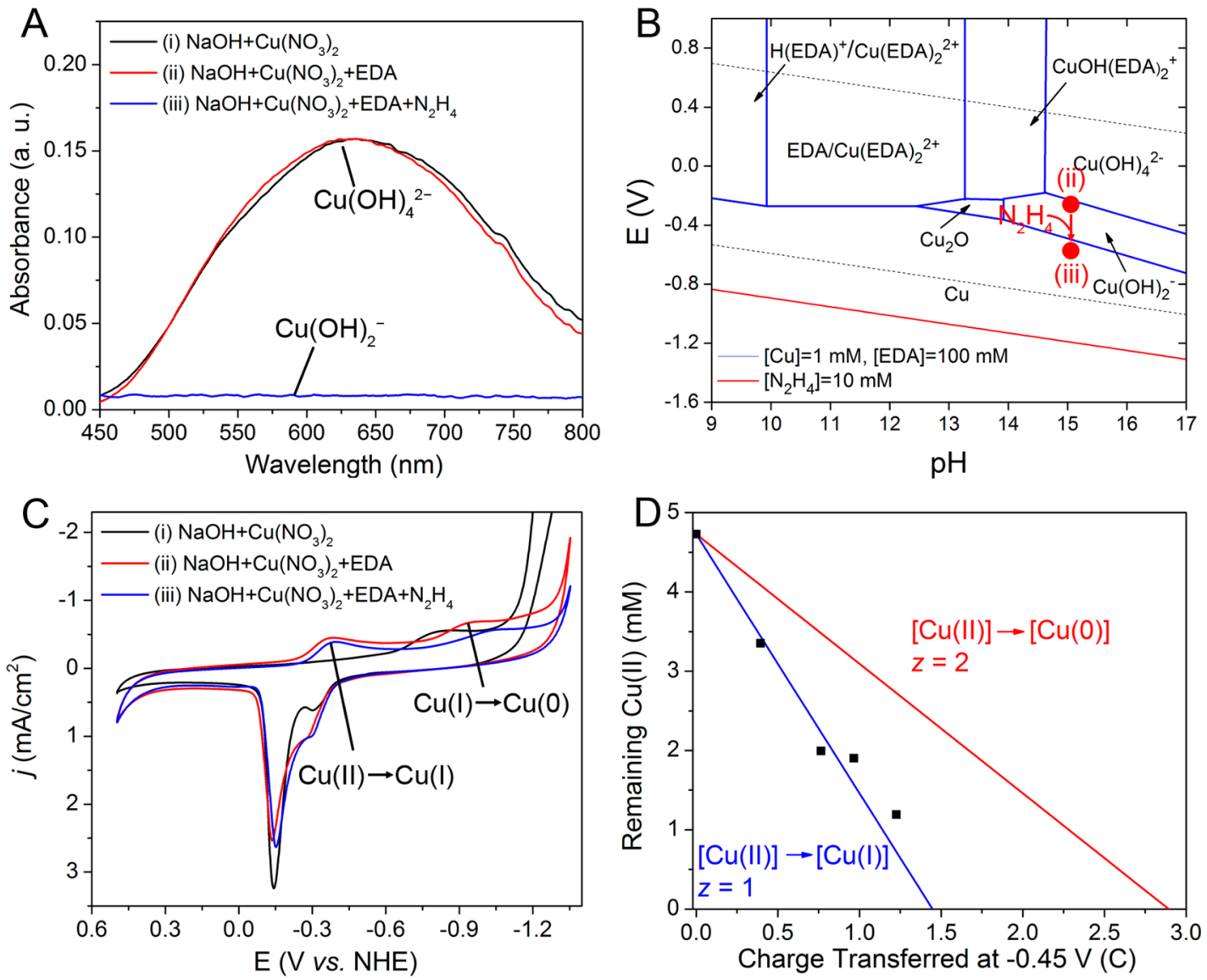

Figure 3. (A) UV-vis absorbance spectra of (i) $14.3 \mathrm{M} \mathrm{NaOH}+4.7 \mathrm{mM} \mathrm{Cu}\left(\mathrm{NO}_{3}\right)_{2}$, (ii) solution (i) + $0.11 \mathrm{M} \mathrm{EDA}$, and (iii) solution (ii) + $25 \mathrm{mM}$ $\mathrm{N}_{2} \mathrm{H}_{4}$. (B) Pourbaix diagram of the Cu-EDA- $\mathrm{H}_{2} \mathrm{O}$ system with $1 \mathrm{mM}$ of $\mathrm{Cu}$ (II) and $100 \mathrm{mM}$ of EDA. (C) CVs of solutions i, ii, and iii at $100 \mathrm{mV}$ $\mathrm{s}^{-1}$. (D) Remaining $\mathrm{Cu}(\mathrm{OH})_{4}{ }^{2-}$ vs charge transferred during the reduction of $\mathrm{Cu}(\mathrm{OH})_{4}{ }^{2-}$ at $-0.45 \mathrm{~V}$. Straight lines represent the theoretical trend for a one- or two-electron reduction of $\mathrm{Cu}(\mathrm{OH})_{4}{ }^{2-}$.

thermocouple was calibrated by comparing the output to a secondary thermocouple located in the cell under the same reaction conditions (Figure S1). By measuring the lengths of the $\mathrm{Cu}$ nanowires in different frames, we determined the growth rate of individual nanowires.

The growth of $\mathrm{Cu}$ nanowires was examined under various temperatures, concentrations of $\mathrm{Cu}$ ions $([\mathrm{Cu}(\mathrm{II})])$, and concentrations of hydrazine $\left(\left[\mathrm{N}_{2} \mathrm{H}_{4}\right]\right)$. As seen in Figure $2 \mathrm{~A}$, the axial growth rate of the $\mathrm{Cu}$ nanowires is constant over time; this was the case for all the experimental conditions for which we show data in Figure 2. When the reaction was carried out with $[\mathrm{Cu}(\mathrm{II})]=4.7 \mathrm{mM}$ and $\left[\mathrm{N}_{2} \mathrm{H}_{4}\right]=25 \mathrm{mM}$ at $343 \mathrm{~K}$, the $\mathrm{Cu}$ nanowires grew at a rate $(\mathrm{d} L / \mathrm{d} t$, where $L$ is the nanowire length and $t$ is the growth time) of $86 \pm 4 \mathrm{~nm} \mathrm{~s}^{-1}$. If [Cu(II)] was increased from 1.9 to $5.6 \mathrm{mM}$ while keeping $\left[\mathrm{N}_{2} \mathrm{H}_{4}\right]$ and temperature $(T)$ constant, the growth rate increased linearly from 17 to $103 \mathrm{~nm} \mathrm{~s}^{-1}$ with a slope of $24 \mathrm{~nm} \mathrm{~s}^{-1} \mathrm{mM}^{-1}$ (Figure $2 B)$. In contrast, the growth rate is independent of $\left[\mathrm{N}_{2} \mathrm{H}_{4}\right]$ between 19.8 and $62.6 \mathrm{mM}$ (Figure 2C), indicating that the reduction of the ionic copper precursor is not the rate-limiting step responsible for nanowire growth. The growth rate is also temperature dependent, and increases with increasing temperature from 333 to $363 \mathrm{~K}$ (Figure 2D). The log of the growth rate is linear with respect to the reciprocal of the temperature with a slope of $-600 \mathrm{~nm} \mathrm{~K} \mathrm{~s}{ }^{-1}$ at $[\mathrm{Cu}(\mathrm{II})]=4.7 \mathrm{mM}$ and $\left[\mathrm{N}_{2} \mathrm{H}_{4}\right]=25 \mathrm{mM}$. Cu nanowires do not form outside of the range of concentrations and temperatures shown in Figure 2BD.

To facilitate the further interpretation of this real-time growth data, we will first provide additional experimental results to show that the species adding to the $\mathrm{Cu}$ nanowires is $\mathrm{Cu}(\mathrm{OH})_{2}{ }^{-}$. Prior to the addition of EDA and $\mathrm{N}_{2} \mathrm{H}_{4}$, the solution of $\mathrm{Cu}(\mathrm{II})$ in concentrated $\mathrm{NaOH}(\mathrm{pH} \sim 15)$ appears deep blue, with a broad absorption peak at $\sim 650 \mathrm{~nm}$ (curve i, Figure $3 \mathrm{~A}$ ). This absorption spectrum is consistent with the formation of a $\mathrm{Cu}(\mathrm{OH})_{4}{ }^{2-}$ complex. $^{39}$ After addition of EDA there is negligible change in the absorption spectrum (curve ii, Figure $3 \mathrm{~A}$ ). By titrating $\mathrm{NaOH}$ into a solution containing EDA and $\mathrm{Cu}(\mathrm{II})$, we can observe that there is no spectral difference between a solution of $\mathrm{Cu}(\mathrm{II})$ and $\mathrm{NaOH}$ with or without EDA at a $[\mathrm{NaOH}]>14.3 \mathrm{M}$ (Figure S2). These results indicate that EDA does not coordinate to $\mathrm{Cu}$ (II) under the conditions used for the $\mathrm{Cu}$ nanowire synthesis.

If $\mathrm{N}_{2} \mathrm{H}_{4}$ is added to the blue solution containing $\mathrm{NaOH}$, EDA, and $\mathrm{Cu}(\mathrm{II})$, the solution turns colorless and the absorbance peak disappears (curve iii, Figure $3 \mathrm{~A}$ ). This spectral change indicates that the colored $\mathrm{Cu}(\mathrm{OH})_{4}{ }^{2-}$ complex has been reduced to a colorless $\mathrm{Cu}(\mathrm{I})$ complex. The color change is accompanied by the formation of $\mathrm{N}_{2}$ bubbles from the oxidation of $\mathrm{N}_{2} \mathrm{H}_{4}$. The Pourbaix diagram of the $\mathrm{Cu}-\mathrm{EDA}-$ $\mathrm{H}_{2} \mathrm{O}$ system indicates this $\mathrm{Cu}(\mathrm{I})$ species is $\mathrm{Cu}(\mathrm{OH})_{2}{ }^{-}$at $\mathrm{pH}=$ $\sim 15$ (Figure 3B, see the Supporting Information for the calculations). The clear reaction solution remains relatively 
stable at room temperature, and neither $\mathrm{Cu}$ nanowires nor nanoparticles form for several hours. In contrast, rapid precipitation of $\mathrm{Cu}_{2} \mathrm{O}$ octahedra occurs in the absence of EDA. $^{36}$ One possible explanation of this is that EDA enhanced the dissolution of $\mathrm{Cu}_{2} \mathrm{O}$ nanoparticles to give $\mathrm{Cu}(\mathrm{EDA})_{2}{ }^{+40}$ which is labile toward $\mathrm{OH}^{-}$substitution:

$$
\begin{aligned}
& \mathrm{Cu}_{2} \mathrm{O}+4 \mathrm{EDA}+\mathrm{H}_{2} \mathrm{O} \rightarrow 2 \mathrm{Cu}(\mathrm{EDA})_{2}^{+}+2 \mathrm{OH}^{-} \\
& \mathrm{Cu}(\mathrm{EDA})_{2}^{+}+2 \mathrm{OH}^{-} \rightarrow \mathrm{Cu}(\mathrm{OH})_{2}^{-}+2 \mathrm{EDA}
\end{aligned}
$$

EDA was also observed to stabilize $\mathrm{Cu}(\mathrm{OH})_{2}{ }^{-}$during cyclic voltammetry $(\mathrm{CV})$. A cyclic voltammogram of $\mathrm{Cu}(\mathrm{II})$ in 14.3 $\mathrm{M} \mathrm{NaOH}$ exhibits a broad reduction peak at $\sim-0.8 \mathrm{~V}$ vs NHE, resulting in the deposition of $\mathrm{Cu}(0)$ on the electrode (curve $\mathrm{i}$, Figure 3C). Because of the broad nature of the peak, it was difficult to determine if $\mathrm{Cu}(\mathrm{II})$ was reduced to $\mathrm{Cu}(0)$ directly or through a $\mathrm{Cu}(\mathrm{I})$ intermediate. In the reverse scan, sequential peaks corresponding to the oxidation of $\mathrm{Cu}(0)$ to $\mathrm{Cu}(\mathrm{I})$ and $\mathrm{Cu}$ (II) were observed. Upon addition of EDA, the broad reduction peak was split into two distinct peaks at -0.4 and $-1.0 \mathrm{~V}$ (curve ii, Figure 3C). Upon further addition of $\mathrm{N}_{2} \mathrm{H}_{4}$ to the solution containing $\mathrm{EDA}, \mathrm{NaOH}$, and $\mathrm{Cu}\left(\mathrm{NO}_{3}\right)_{2}$, the $\mathrm{CV}$ profile exhibits no change (curve iii, Figure $3 \mathrm{C}$ ).

In contrast to the second peak at $-1.0 \mathrm{~V}$ that results in the heterogeneous deposition of $\mathrm{Cu}(0)$, the first peak at $-0.4 \mathrm{~V}$ is a homogeneous process that arises from the reduction of $\mathrm{Cu}(\mathrm{OH})_{4}{ }^{2-}$ to $\mathrm{Cu}(\mathrm{OH})_{2}{ }^{-}$. By scanning the potential between 0.1 and $-0.7 \mathrm{~V}$ to avoid overlap with the reduction to $\mathrm{Cu}(0)$ at $-1.0 \mathrm{~V}$, we observed well-defined reversible redox peaks for the $\mathrm{Cu}(\mathrm{OH})_{4}{ }^{2-} / \mathrm{Cu}(\mathrm{OH})_{2}{ }^{-}$redox couple. The peak current density $\left(j_{p}\right)$ was proportional to the square root of the scan rate $\left(v^{1 / 2}\right)$, indicating a diffusion-controlled redox process (Figure S3). Sustained electrolysis at $-0.45 \mathrm{~V}$ resulted in conversion of the solution color from deep blue (indicating the presence of $\mathrm{Cu}(\mathrm{OH})_{4}{ }^{2-}$ ) to nearly clear (indicating the presence of $\left.\mathrm{Cu}(\mathrm{OH})_{2}{ }^{-}\right)$. By correlating the amount of charge transferred at $-0.45 \mathrm{~V}$ to the concentration of $\mathrm{Cu}(\mathrm{OH})_{4}{ }^{2-}$ that remained in the solution (Figure S4), we confirmed that the reduction processes occurring at $-0.4 \mathrm{~V}$ is a one-electron reduction process (Figure $3 \mathrm{D}$ ), consistent with reduction of $\mathrm{Cu}(\mathrm{OH})_{4}{ }^{2-}$ to $\mathrm{Cu}(\mathrm{OH})_{2}{ }^{-}$.

Now that we have partly addressed the question of the species that adds to the $\mathrm{Cu}$ nanowire, we turn our attention to showing that the growth of $\mathrm{Cu}$ nanowires is limited by the rate of diffusion of $\mathrm{Cu}(\mathrm{OH})_{2}{ }^{-}$to the surface of the nanowire. After they sprout from the seeds, $\mathrm{Cu}$ nanowires grow with a relatively uniform diameter (which is always smaller than the diameter of the seed).$^{38}$ Within the range of growth conditions studied here, which encompass the range of conditions for which $\mathrm{Cu}$ nanowires formed, the diameters of the $\mathrm{Cu}$ nanowires appear almost constant (see Table S1). From over 300 measurements, the radius of the $\mathrm{Cu}$ nanowires grown in the reaction cell was determined to be $30.6 \pm 6.0 \mathrm{~nm}$. Each growing nanowire can thus be approximated as an ultramicroeletrode with a constant diameter and tip surface area $(A)$. According to previous HRTEM characterization, the $\mathrm{Cu}$ nanowires have a pentagonal cross section. ${ }^{36}$ With an average nanowire radius of $r=30.6$ $\mathrm{nm}$, the area at the end of the nanowire is $A=3.44 r^{2}=3221$ $\mathrm{nm}^{2}$ (see Figure S5 and S6). The electrochemical potential of the nanowire electrode is fixed at the redox potential of $\mathrm{N}_{2} \mathrm{H}_{4}$, resulting in a constant potential for reduction of $\mathrm{Cu}(\mathrm{OH})_{2}{ }^{-}$. According to Faraday's Law, the mass added $(m)$ to the nanowire tip is proportional to the amount of charge transferred $(Q)$ :

$$
m=\frac{Q M}{z F}=\frac{I t M}{z F}
$$

where $I$ is the current passed through the nanowire, $F$ is the Faraday constant, $M$ is the molar mass of copper, and $z$ (equal to 1$)$ is the number of electrons necessary to reduce $\mathrm{Cu}(\mathrm{OH})_{2}{ }^{-}$ to $\mathrm{Cu}(0)$.

To see if the growth of $\mathrm{Cu}$ nanowires is limited by the rate of diffusion, we compare the growth rate of a nanowire to the diffusion-limited maximum growth rate. At an ultramicroeletrode, the diffusion-limited steady-state current derived from Fick's second law is given by ${ }^{41}$

$$
I=\frac{z F A}{r} D C
$$

where $\mathrm{C}$ is the concentration of $\mathrm{Cu}(\mathrm{OH})_{2}{ }^{-}$, and $\mathrm{D} \approx 0.91 \times$ $10^{-6} \mathrm{~cm}^{2} \mathrm{~s}^{-1}$ is the diffusion coefficient for $\mathrm{Cu}(\mathrm{OH})_{2}{ }^{-}$at $343 \mathrm{~K}$. We determined the diffusion coefficient for $\mathrm{Cu}(\mathrm{OH})_{2}{ }^{-}$from the slope of the plot of $j_{p} v s v^{1 / 2}$ (Figure S3) and the RandlesSevcik equation (Table S2): ${ }^{42}$

$$
j_{p}=0.4463 z F C\left(\frac{z F v D}{R T}\right)^{1 / 2}
$$

where $R$ is the gas constant. The diffusion coefficient obtained here is comparable to those of reported for other $\mathrm{Cu}$ complexes in the literature (Table S3). ${ }^{43}$

By combining eq 2 and $\mathrm{d} m=2.79 \rho r^{2} \mathrm{~d} L$ with eq 1 , the diffusion-limited rate of nanowire growth at a given temperature is

$$
\frac{\mathrm{d} L}{\mathrm{~d} t}=1.23\left(\frac{M}{\rho r}\right) D C
$$

where $\rho$ is the density of copper. With eq 4, the maximum growth rate of a nanowire is linearly dependent on $[\mathrm{Cu}(\mathrm{II})]$ with a slope of $26 \mathrm{~nm} \mathrm{~s}^{-1} \mathrm{mM}^{-1}$ at $343 \mathrm{~K}$. This is only slightly larger than the experimentally measured nanowire growth rate dependence on $[\mathrm{Cu}(\mathrm{II})]$ of $24 \mathrm{~nm} \mathrm{~s}^{-1} \mathrm{mM}^{-1}$ at $343 \mathrm{~K}$ (Figure 2B). These data are very strong evidence in support of a model by which $\mathrm{Cu}$ nanowires grow through the diffusion limited addition of $\mathrm{Cu}(\mathrm{OH})_{2}{ }^{-}$to the end of the nanowire.

Additional evidence for the diffusion-controlled growth of $\mathrm{Cu}$ nanowires comes from the low activation energy, $E_{a}$ for nanowire growth. From eq 4 and $D=D_{0} \mathrm{e}^{-E a / R T}\left(D_{0}\right.$ is the frequency factor), we can show that the log of the growth rate is linearly dependent on the reciprocal of temperature at fixed reagent concentrations:

$$
\ln \left(\frac{\mathrm{d} L}{\mathrm{~d} t}\right)=\frac{\left(-\frac{E_{\mathrm{a}}}{R}\right)}{T}+\ln \left[1.23\left(\frac{M C}{\rho r}\right) D_{0}\right]
$$

By fitting the data in Figure 2D with eq 5, we determined the activation energy for $\mathrm{Cu}$ nanowire growth to be $11.5 \mathrm{~kJ} \mathrm{~mol}^{-1}$ (Table S4). Such a low value indicates a diffusion-controlled process. $^{44}$

Finally, we show that $\mathrm{N}_{2} \mathrm{H}_{4}$ provides the thermodynamic driving force for reduction of the $\mathrm{Cu}(\mathrm{OH})_{2}{ }^{-}$intermediate at elevated temperatures. We verified this by measuring the open circuit potential (OCP) in the growth solution with a $\mathrm{Cu}$ nanowire network on a glass substrate as the working electrode. ${ }^{45-47}$ An OCP of $-0.30 \mathrm{~V}$ was measured in a 
solution of $\mathrm{Cu}(\mathrm{II}) / \mathrm{EDA} / \mathrm{NaOH}$, a potential that stabilizes $\mathrm{Cu}(\mathrm{II})$ as indicated by the Pourbaix diagram (Figure 3B). Addition of $\mathrm{N}_{2} \mathrm{H}_{4}$ lowered the OCP to $-0.62 \mathrm{~V}$, a potential sufficient to reduce $\mathrm{Cu}(\mathrm{II})$ to $\mathrm{Cu}(\mathrm{I})$, but insufficient to further reduce $\mathrm{Cu}(\mathrm{I})$ to $\mathrm{Cu}(0)$ at room temperature. This is consistent with the observation that the clear reaction solution containing $\mathrm{Cu}(\mathrm{OH})_{2}{ }^{-}$is stable at room temperature. However, elevating the solution temperature in the electrochemical cell to $343 \mathrm{~K}$ decreased the OCP to $-0.70 \mathrm{~V}$, suggesting that increasing the temperature increased the potential of $\mathrm{N}_{2} \mathrm{H}_{4}$ to give up its electrons to $\mathrm{Cu}(\mathrm{I})$. In addition, the increase in temperature shifted the onset potential of reduction of $\mathrm{Cu}(\mathrm{I})$ to $\mathrm{Cu}(0)$ from -0.75 to $-0.68 \mathrm{~V}$. These two effects together contribute to the reduction of $\mathrm{Cu}(\mathrm{OH})_{2}{ }^{-}$to metallic copper at elevated temperatures.

We summarize the above results and analysis with the $\mathrm{Cu}$ nanowire growth model illustrated in Scheme 1. Oxidation of

\section{Scheme 1. Growth Model of $\mathrm{Cu}$ Nanowires}

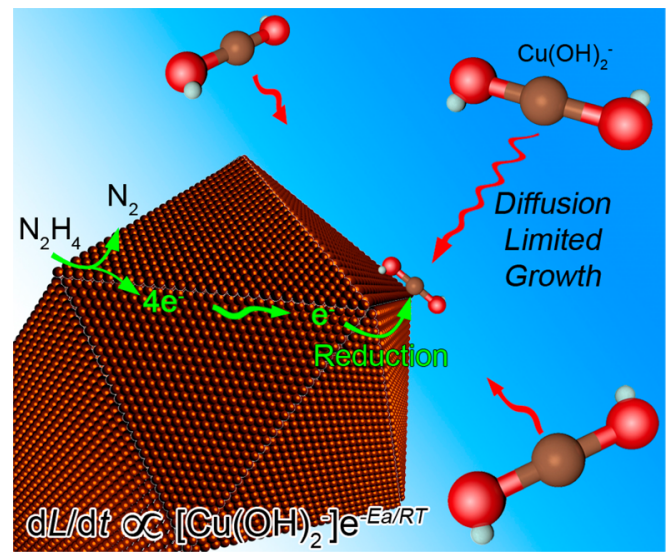

$\mathrm{N}_{2} \mathrm{H}_{4}$ provides the electrochemical potential for reduction of $\mathrm{Cu}(\mathrm{I})$ to $\mathrm{Cu}(0)$ at the end of the nanowire at $343 \mathrm{~K}$. Once this potential is in place, the growth rate is kinetically limited not by the concentration of the reducing agent, $\mathrm{N}_{2} \mathrm{H}_{4}$, but by the diffusion of $\mathrm{Cu}(\mathrm{OH})_{2}{ }^{-}$to the end of the nanowire.

In conclusion, we demonstrate the first diffusion-controlled model for nanowire growth in solution. We further provide spectroscopic and electrochemical data that suggest that $\mathrm{Cu}$ nanowires grow through the addition of $\mathrm{Cu}(\mathrm{OH})_{2}{ }^{-}$. As the nanowire growth does not depend on the concentration of the reducing agent, $\mathrm{N}_{2} \mathrm{H}_{4}$, the role of this species is to provide the potential necessary to reduce $\mathrm{Cu}(\mathrm{OH})_{4}{ }^{2-}$ to $\mathrm{Cu}(\mathrm{OH})_{2}{ }^{-}$at room temperature, and $\mathrm{Cu}(\mathrm{OH})_{2}{ }^{-}$to $\mathrm{Cu}(0)$ at elevated temperatures. We now know what species adds to a growing copper nanowire, the rate limiting step of nanowire growth, and the activation energy for nanowire growth. From previous work, it is clear that EDA affects the growth rate and aspect ratio of copper nanowires, ${ }^{38}$ but there is still no direct experimental evidence to verify why the nanowire grows in one dimension. Nevertheless, we expect this model of diffusioncontrolled growth can be applied to better understand a wide variety of nanostructure syntheses, leading to better control over the assembly of atoms into well-defined morphologies with desirable properties.

\section{ASSOCIATED CONTENT}

\section{Supporting Information}

Detailed description of experimental methods, additional figures, and a movie showing real time growth of $\mathrm{Cu}$ nanowires. This material is available free of charge via the Internet at http://pubs.acs.org.

\section{AUTHOR INFORMATION}

\section{Corresponding Author}

*(B.J.W.) E-mail: Benjamin.wiley@duke.edu.

\section{Author Contributions}

${ }^{\perp}$ These authors contributed equally. The manuscript was written through contributions of all authors. All authors have given approval to the final version of the manuscript.

Notes

The authors declare no competing financial interests.

\section{ACKNOWLEDGMENTS}

This work was supported in part by the National Science Foundation's (NSF's) Research Triangle MRSEC (DMR1121107), an NSF CAREER award (DMR-1253534), and NSF Grant No. ECCS-1344745. Y.-C.H. was supported by the research fund from KERI (No. 13-02-N0104-01).

\section{REFERENCES}

(1) Whitesides, G. M.; Mathias, J. P.; Seto, C. T. Science 1991, 254, 1312.

(2) Whitesides, G. M.; Grzybowski, B. Science 2002, 295, 2418.

(3) Hu, J.; Odom, T. W.; Lieber, C. M. Acc. Chem. Res. 1999, 32, 435.

(4) Rao, C. N. R.; Deepak, F. L.; Gundiah, G.; Govindaraj, A. Prog. Solid State Chem. 2003, 31, 5.

(5) Xia, Y.; Yang, P.; Sun, Y.; Wu, Y.; Mayers, B.; Gates, B.; Yin, Y.; Kim, F.; Yan, H. Adv. Mater. 2003, 15, 353.

(6) Law, M.; Goldberger, J.; Yang, P. Annu. Rev. Mater. Res. 2004, 34, 83.

(7) Tang, Z.; Kotov, N. A. Adv. Mater. 2005, 17, 951.

(8) Cademartiri, L.; Ozin, G. A. Adv. Mater. 2009, 21, 1013.

(9) Repko, A.; Cademartiri, L. Can. J. Chem. 2012, 90, 1032.

(10) Morales, A. M.; Lieber, C. M. Science 1998, 279, 208.

(11) Kodambaka, S.; Tersoff, J.; Reuter, M. C.; Ross, F. M. Science 2007, 316, 729.

(12) Ross, F. M. Rep. Prog. Phys. 2010, 73, 114501.

(13) Tang, Z.; Kotov, N. A.; Giersig, M. Science 2002, 297, 237.

(14) Koh, W.-K.; Bartnik, A. C.; Wise, F. W.; Murray, C. B. J. Am. Chem. Soc. 2010, 132, 3909.

(15) Yuwono, V. M.; Burrows, N. D.; Soltis, J. A.; Penn, R. L. J. Am. Chem. Soc. 2010, 132, 2163.

(16) Cademartiri, L.; Guerin, G.; Bishop, K. J. M.; Winnik, M. A.; Ozin, G. A. J. Am. Chem. Soc. 2012, 134, 9327.

(17) http://www.cambrios.com/.

(18) Leem, D.-S.; Edwards, A.; Faist, M.; Nelson, J.; Bradley, D. D. C.; de Mello, J. C. Adv. Mater. 2011, 23, 4371.

(19) Yang, L.; Zhang, T.; Zhou, H.; Price, S. C.; Wiley, B. J.; You, W. ACS Appl. Mater. Interfaces 2011, 3, 4075.

(20) Song, M.; You, D. S.; Lim, K.; Park, S.; Jung, S.; Kim, C. S.; Kim, D.-H.; Kim, D.-G.; Kim, J.-K.; Park, J.; Kang, Y.-C.; Heo, J.; Jin, S.-H.; Park, J. H.; Kang, J.-W. Adv. Funct. Mater. 2013, 23, 4177.

(21) Kodambaka, S.; Tersoff, J.; Reuter, M. C.; Ross, F. M. Phys. Rev. Lett. 2006, 96, 096105.

(22) Eswaramoorthy, S. K.; Howe, J. M.; Muralidharan, G. Science 2007, 318, 1437.

(23) Dubrovskii, V. G.; Sibirev, N. V.; Harmand, J. C.; Glas, F. Phys. Rev. B 2008, 78, 235301.

(24) Liao, H.-G.; Cui, L.; Whitelam, S.; Zheng, H. Science 2012, 336, 1011. 
(25) Wang, H.; Zepeda-Ruiz, L. A.; Gilmer, G. H.; Upmanyu, M. Nat. Commun. 2013, 4, 1956.

(26) Stach, E. A.; Pauzauskie, P. J.; Kuykendall, T.; Goldberger, J.; He, R.; Yang, P. Nano Lett. 2003, 3, 867.

(27) Zheng, H.; Smith, R. K.; Jun, Y.-W.; Kisielowski, C.; Dahmen, U.; Alivisatos, A. P. Science 2009, 324, 1309.

(28) Sun, Y.; Wang, Y. Nano Lett. 2011, 11, 4386.

(29) Li, D.; Nielsen, M. H.; Lee, J. R. I.; Frandsen, C.; Banfield, J. F.; De Yoreo, J. J. Science 2012, 336, 1014.

(30) Sun, Y. Mater. Today 2012, 15, 140.

(31) Yuk, J. M.; Park, J.; Ercius, P.; Kim, K.; Hellebusch, D. J.; Crommie, M. F.; Lee, J. Y.; Zettl, A.; Alivisatos, A. P. Science 2012, 336, 61.

(32) Liao, H.-G.; Niu, K.; Zheng, H. Chem. Commun. 2013, 49, 11720.

(33) Liao, H.-G.; Zheng, H. J. Am. Chem. Soc. 2013, 135, 5038.

(34) Rathmell, A. R.; Bergin, S. M.; Hua, Y.-L.; Li, Z.-Y.; Wiley, B. J. Adv. Mater. 2010, 22, 3558.

(35) Rathmell, A. R.; Nguyen, M.; Chi, M.; Wiley, B. J. Nano Lett. 2012, 12, 3193.

(36) Ye, S.; Rathmell, A. R.; Ha, Y.-C.; Wilson, A. R.; Wiley, B. J. Small 2014, 10, 1771.

(37) Sun, Y.; Mayers, B.; Herricks, T.; Xia, Y. Nano Lett. 2003, 3, 955.

(38) Ye, S.; Rathmell, A. R.; Stewart, I. E.; Ha, Y.-C.; Wilson, A. R.; Chen, Z.; Wiley, B. J. Chem. Commun. 2014, 50, 2562.

(39) Chao, Y.-Y. H.; Kearns, D. R. J. Phys. Chem. 1977, 81, 666.

(40) Aksu, S.; Doyle, F. M. J. Electrochem. Soc. 2002, 149, B340.

(41) Bard, A. J.; Faulkner, L. R. Electrochemical Methods: Fundamentals and Applications, 2nd ed.; John Wiley \& Sons, Inc.: New York, 2001.

(42) Zanello, P. Inorganic Electrochemistry: Theory, Practice and Application; The Royal Society of Chemistry: London, 2003.

(43) Norkus, E. J. Appl. Electrochem. 2000, 30, 1163.

(44) Bamford, C. H.; Tipper, C. F. H.; Compton, R. G. in Comprehensive Chemical Kinetics: Diffusion-Limited Reactions; Elsevier: Amsterdam, 1985; Vol. 25.

(45) Chen, Z.; Rathmell, A. R.; Ye, S.; Wilson, A. R.; Wiley, B. J. Angew. Chem., Int. Ed. 2013, 52, 13708.

(46) Chen, Z.; Ye, S.; Wilson, A. R.; Ha, Y.-C.; Wiley, B. J. Energy Environ. Sci. 2014, 7, 1461.

(47) Rathmell, A. R.; Wiley, B. J. Adv. Mater. 2011, 23, 4798. 